\title{
O programa de Residência Pedagógica: relato de experiência no ensino de língua inglesa em um colégio público Paranaense
}

The Pedagogical Residence program: report of experience in english language teaching in a Paranaense public school

Flávia Bissi de Oliveira

Sandra Maria Coelho de Souza Moser

Resumo: O presente trabalho é um relato baseado nas experiências vividas por uma graduanda do curso de Letras, da Universidade Estadual de Maringá (UEM), no Programa de Residência Pedagógica no ensino de língua inglesa. Foi realizado nas turmas de $3^{\circ}$ ano (ensino médio) em uma escola pública. O programa visa induzir o aperfeiçoamento da formação prática nos cursos de licenciatura, promovendo a imersão do acadêmico na escola de educação básica, a partir da segunda metade de seu curso (CAPES, 2018). Assim, a estudante relata a respeito do funcionamento do colégio, do desempenho e a forma de ensino da professora da classe, além de suas aprendizagens e seus desafios. São apresentadas considerações de autores, como Libâneo (2012), Silvestre (2011) e Wengzynski e Tozetto (2012). As experiências vivenciadas mostraram a relevância do programa para o desenvolvimento na formação de futuros professores, uma vez que ele contempla habilidades e competências que auxiliam na prática docente.

Palavras-chave: Programa Residência Pedagógica. Relato de experiência. Língua Inglesa.

Abstract: The present work is a report based on the experienced by a student who is majoring Language course at the State University of Maringá (UEM), in the Pedagogical Residency Program in English language teaching. It was carried out in the 3rd year classes (high school) in a public school. The objective of this program is to induce the improvement of practical training in licentiate degree courses, promoting the immersion of the academic in the basic education school, from the second half of its course (CAPES, 2018). Thus, the student reports about the functioning of the school, the teacher's performance and her way of teaching in class, and her learnings and challenges. Authors' considerations are presented, such as Libâneo (2012), Silvestre (2011) e Wengzynski e Tozetto (2012). The experiences showed the relevance of this program for the development in the formation of future teachers, since it contemplates skills and competences that help in the teaching practice.

Keywords: Pedagogical Residency Program. Experience report. English language.

\section{Introdução}

Cada vez mais as universidades têm aumentado ações que integram a Política Nacional de Formação de Professores a fim de conduzir o aperfeiçoamento da formação prática dos discentes dos cursos de licenciatura. Essa promoção contribui para a imersão do acadêmico nas escolas de educação básica, seu futuro contexto real de trabalho. Uma dessas ações foi a 
criação do Programa de Residência Pedagógica, foco deste trabalho. Segundo Hurbert, Fernandes e Goettems (2015),

De acordo com a política de formação de professores explicitada na Lei de Diretrizes e Bases da Educação Nacional Lei $N^{\circ}$ 9.394/96 - LDB, a formação do professor precisa estar fundamentada em uma educação para o convívio social entre diferentes culturas reconhecendo os valores e os direitos da humanidade (HURBERT; FERNANDES; GOETTEMS, 2015, p. 3).

Os projetos e os programas de extensão desenvolvidos pelas universidades são alguns dos caminhos que colaboram para a formação dos acadêmicos de licenciatura, uma vez que integra a teoria, aprendida no ambiente acadêmico, e a prática de sua profissão numa comunicação com a sociedade. Isso propicia uma permuta entre os saberes de ambos. De acordo com Manchur, Suriani e Cunha (2013),

\begin{abstract}
Através dessa ação acontece a socialização e construção de novos conhecimentos. Para os cursos de licenciatura, a extensão favorece o contato direto para o desenvolvimento da prática docente, que possibilita o desenvolvimento de metodologias de ensino que potencializam a sua formação acadêmica. (MANCHUR; SURIANI; CUNHA, 2013, p. 338)
\end{abstract}

Levando em consideração as experiências vivenciadas dentro de programas e projetos universitários, podemos considerar que o professor também é pesquisador. O pesquisador vai refletir a respeito de como ele pode melhorar o ensino, refazer seus métodos para investir na sala de aula, pois não basta ser só professor. Silva, Silva e Queiroz (2016, p.n.) declaram que "[...] o professor pesquisador é aquele que pesquisa ou que reflete sobre a sua prática, que pensa, que elabora em cima dessa prática". Assim, é notório que está havendo uma transformação na forma de se pensar e formar um professor.

A luz do exposto, o presente trabalho relata as experiências vivenciadas por uma graduanda (pseudônimo Letícia ${ }^{1}$ ) do quarto ano do curso de Letras, da Universidade Estadual de Maringá (UEM), que participou do Programa de

\footnotetext{
${ }^{1} \mathrm{O}$ nome fictício foi usado a fim de preservar a identidade e os princípios éticos da pesquisa.
} 
Residência Pedagógica no ensino de língua inglesa (LI). A acadêmica refletiu criticamente sobre suas experiências vivenciadas durante 0 programa supracitado. Mediante a isso, ela relatou sobre o funcionamento da escola, sobre o desempenho e a forma de ensino da professora da turma, que também era sua preceptora (identificada com o pseudônimo Fernanda), além de suas aprendizagens e de seus desafios. A atuação da estudante foi realizada em um colégio público paranaense, na cidade de Maringá-PR, no ano de 2019, entre os meses de fevereiro e dezembro.

O presente relato apresenta a atuação da discente na segunda etapa do Programa de Residência Pedagógica. A acadêmica lecionou em duas turmas, no $3^{\circ}$ ano $A$ e no $3^{\circ}$ ano $B$, do ensino médio. A carga horária se dava da seguinte forma: três horas/aulas por semana dentro da sala e mais uma de hora atividade no colégio. Além do $3^{\circ}$ ano, ela também participava das aulas na turma do $1^{\circ}$ ano $B$ do ensino médio. Entretanto, não ministrava aula, somente auxiliava. Isto se deve ao fato de que essa turma pertencia a outros residentes, mas ela acompanhava essa classe a fim de cumprir a carga horária do programa. Leticia também compartilhava as três turmas com outros colegas residentes.

\section{O Programa de Residência Pedagógica}

O Programa de Residência Pedagógica foi elaborado pela Coordenação de Aperfeiçoamento de Pessoal de Nível Superior (CAPES) e tem como objetivo a implementação de projetos inovadores nas Instituições de Ensino Superior (IES), a fim de estimular a articulação entre teoria e prática nos cursos de licenciatura, em parceria com as escolas públicas de educação básica.

Conferidas pela Lei $n^{\circ} 8.405$, de 09 de janeiro de 1992, e pelo Estatuto aprovado pelo Decreto $n^{\circ} 8.977$, de 30 de janeiro de 2017, por meio de sua Diretoria de Formação de Professores da Educação Básica (DEB), no uso de suas atribuições, torna pública a seleção de Instituições de Ensino Superior interessadas em implementar Projetos Institucionais de Residência Pedagógica, conforme processo de $n^{\circ}$. 23038.001459/2018-36 e de acordo com as normas deste Edital, da Lei $n^{\circ} 8.666$ de 21 de junho de 1993, da Lei 9.784, de 29 de janeiro de 1999, da Lei 13.473 de 08 de agosto de 2017, 
do $02 / 2015$, de $1^{\circ}$ de julho de 2015 da Portaria Capes $n^{\circ} 38$ de 28 de fevereiro de 2018 e demais dispositivos aplicáveis à matéria (CAPES, 2018).

Ademais, o programa visa o aprimoramento do estágio curricular supervisionado nos cursos de licenciatura, visto que o estágio tem como objetivo preparar o acadêmico para a inserção na profissão na qual atuará além de permitir ao discente analisar e refletir sobre seu futuro ambiente de trabalho. Também há uma necessidade dos graduandos de experienciar a prática docente no contexto escolar, uma vez que muitos nunca tiveram esse contato. Á vista disso, Wengzynski e Tozetto (2012, p. 9) declaram que as escolas desenvolvem um papel muito importante nesse processo de formação.

O Residência possui carga horária de 440 horas de atividades distribuídas da seguinte forma: 60 horas destinadas à ambientação na escola; 320 horas de imersão, sendo 100 de regência, que incluirá o planejamento e execução de pelo menos uma intervenção pedagógica; e 60 horas destinadas à elaboração de relatório final, avaliação e socialização de atividades (CAPES, 2018). No ano de 2018, a Universidade Estadual de Maringá foi beneficiada com 264 bolsas para os acadêmicos de licenciatura, 33 bolsas para professores preceptores da Educação Básica e 14 bolsas para professores coordenadores da UEM dos cursos de Língua Inglesa, História, Educação Física, Geografia, Pedagogia, Ciências Biológicas e Música. O Programa abrange 11 instituições públicas de ensino da educação básica, rede municipal e estadual, dos municípios de Maringá, Sarandi, Cianorte e Ivaiporã (PUPIM, 2018).

As atividades contempladas pelo programa eram regência de classe - os residentes eram amparados pelo docente orientador do curso de formação e pelo preceptor da escola -, planejamento e execução de atividades, planos de aula, sequências didáticas, projetos de ensino e atividades de avaliação dos alunos. Os residentes tinham reuniões reflexivas semanalmente, com a orientadora do projeto, que objetivava a discussão do desenvolvimento do programa nas escolas, a título de exemplo a elaboração de planos de aulas e o processo de ensino e aprendizagem dos alunos. De acordo com Libâneo (2012, p. 85) a reflexão é uma peça fundamental na formação dos docentes, 
A reflexividade se insere como um dos elementos de formação profissional dos professores, que, na maioria das vezes, entende-se como um processo articulado de ação-reflexãoação. [...] Os professores aprendem sua profissão por vários caminhos, com a contribuição das teorias conhecidas de ensino e aprendizagem e inclusive com a própria experiência (LIBÂNEO, 2012, p. 85-86).

Um ponto a ser destacado é que o programa foi realizado com apoio da Coordenação de Aperfeiçoamento de Pessoal de Nível Superior. Assim, é importante agradecer à CAPES pela concessão das bolsas aos alunos e, principalmente, por contribuir com a criação e o desenvolvimento deste programa, uma vez que o Residência Pedagógica é tão significativo na vida profissional dos docentes em formação inicial além de proporcionar uma experiência excepcional.

\section{Resultados da experiência e discussão}

\section{O contexto escolar e a professora preceptora}

A execução de qualquer ofício envolve a prática, assim, a atuação do discente em formação inicial em diferentes contextos é muito significativa. Dessa forma, com as ações desenvolvidas pelas universidades, o futuro professor tem a possibilidade de observar, planejar e ministrar aulas. De acordo com Charlot (2012, p. 104). "Os professores estão se formando mais com outros professores dentro das escolas do que nas aulas das universidades ou dos institutos de formação".

Tendo como base as informações supracitadas, a participante do programa relatou que atuar no ambiente escolar ajudou muito no seu aperfeiçoamento prático de sua formação enquanto docente inicial, visto que estar em contato com o real contexto de trabalho mostrou a ela seus futuros desafios. Essa não foi sua primeira experiência com o ensino básico, visto que, no ano de 2017, ela já tinha participado do Programa Institucional de Bolsas de Iniciação à Docência (PIBID). Mas, Letícia ressaltou que é muito interessante observar os diferentes ambientes escolares, uma vez que cada instituição tem suas particularidades, o que as tornam únicas. Ela também disse que essa 
experiência fez com que ela refletisse bastante a respeito de como atuar em sala de aula, em qual método de ensino aplicar ou até mesmo como motivar os alunos.

O ambiente escolar, no qual foi realizado esta ação, localiza-se na periferia da cidade de Maringá-PR. O colégio tem um espaço bem grande, é formado por três blocos: o primeiro com dez salas e uma sala ambiente para biblioteca; o segundo destinado à ala administrativa, com banheiros para uso discente; o terceiro com salas ambientes como Laboratório de Ciências e Educação Artística. As salas são bem conservadas, todavia, elas comportam um grande número de alunos na maioria das turmas, realidade enfrentada pela maior parte das escolas de ensino básico no Brasil. Ainda, isto pode ser prejudicial no ensino- aprendizagem, uma vez que, os professores não conseguem atender todos os alunos com tempo e tranquilidade.

Já em relação à professora responsável pelas turmas e por sua supervisão, a residente declarou que ela não tinha tido nenhuma experiência com o inglês antes de entrar numa sala de aula, nem mesmo fez curso particular, seu único contato com esse idioma foi durante as disciplinas de língua inglesa na universidade em que ela estudou. Leticia destacou essa situação como um tópico importante, pois, nos dias de hoje, é comum ainda que muitos docentes formados em dupla habilitação (Português/Inglês) lecionam disciplinas que não gostam e as ministram somente para completar a carga horária ou porque tal escola está precisando de professor, acarretando em um mal ensino. De acordo com Silvestre (2011),

Formar professores autônomos, conscientes e responsáveis pela própria formação profissional tem sido um desafio [...]". É notável a importância do aprimoramento profissional, pois a falta disso pode fazer com que o professor não tenha motivação e nem disciplina para exercer seu ofício de maneira adequada (SILVESTRE, 2011, p. 1).

Além disso, de acordo com a graduanda, a professora Fernanda trabalhava de forma dedutiva. Ela utilizava uma gramática para passar o conteúdo no quadro e aplicar atividades, raramente fazia o uso do livro didático. Ela explicava de forma clara e de fácil entendimento, retomava o conteúdo da aula anterior para relembrar, entretanto, não ativava os 
conhecimentos prévios dos alunos nem os levavam a pensar sobre o conteúdo que iriam estudar. Muitas metodologias já foram experienciadas, diversas abordagens foram discutidas e experimentadas, todavia, ainda não existe um paradigma que ensina a língua inglesa com excelência (SANTOS et al. 2013, p. 125). No entanto, se o aluno é direcionado a pensar no uso daquele tópico da aula, ele internaliza o conhecimento e não apenas decora.

Conforme a Base Nacional Comum Curricular (BNCC), o intuito do ensino de LI nas escolas é levar os alunos a desenvolverem uma autonomia a fim de fazerem o uso deste idioma como recurso comunicativo. O documento também explana que o estudante necessita aprender uma segunda língua por meio de práticas linguísticas do dia a dia, do seu uso e reflexão sobre elas. Segundo a base, o aprendizado em língua inglesa é muito importante na formação de um indivíduo, visto que é um idioma global.

Aprender a língua inglesa propicia a criação de novas formas de engajamento e participação dos alunos em um mundo social cada vez mais globalizado e plural, em que as fronteiras entre países e interesses pessoais, locais, regionais, nacionais e transnacionais estão cada vez mais difusas e contraditórias. Assim, o estudo da língua inglesa pode possibilitar a todos o acesso aos saberes linguísticos necessários para engajamento e participação, contribuindo para o agenciamento crítico dos estudantes e para o exercício da cidadania ativa, além de ampliar as possibilidades de interação e mobilidade, abrindo novos percursos de construção de conhecimentos e de continuidade nos estudos (BRASIL, 2017, p. 241).

Continuando as reflexões a respeito de suas experiências acerca do ensino de LI, Leticia observou que Fernanda não falava em inglês com a turma em nenhum momento, toda explicação era em português, e nem desenvolvia atividades orais para a classe praticar. É importante salientar que para uma pessoa aprender uma nova língua ela necessita desenvolver competências e habilidades a fim de ter uma formação completa no idioma. Pois, não adianta dominar a escrita e não saber se comunicar com as pessoas, isto é, uma habilidade necessita da outra para que o aprendizado seja pleno. Analisando todas as suas experiências na sala de aula tanto como aluna quanto professora, a universitária relatou que isso não é uma falha somente da preceptora, mas sim de muitos outros docentes. 
De acordo com a BNCC (BRASIL, 2017, p. 8) a competência pode ser definida como "a mobilização de conhecimentos (conceitos e procedimentos), habilidades (práticas, cognitivas e socioemocionais), atitudes e valores para resolver demandas complexas da vida cotidiana, do pleno exercício da cidadania e do mundo do trabalho." Já as habilidades "expressam as aprendizagens essenciais que devem ser asseguradas aos alunos nos diferentes contextos escolares." (BRASIL, 2017, p. 29) É notório que as competências e as habilidades estão correlacionadas na questão dos objetivos de aprendizagem. Sendo assim, é preciso que a escola crie estratégias pertinentes com a intenção de potencializar o aprendizado dos alunos.

Wildgrube et al (2018, n.p) explica que o aprendizado de uma língua estrangeira, neste caso o inglês, é importante proporcionar ao aluno o contato com as habilidades desse idioma. Ela cita writing, listening, speaking, reading como exemplos de habilidades. Segundo os autores (2018, p. 4, apud HOLDEN; ROGERS, 2002) existem também as minihabilidades que em conjunto com as habilidades supracitadas complementam o trabalho de ensino e aprendizagem de uma língua estrangeira. A primeira minihabilidade é a social. Aqui, o aprendiz precisar estar interagido tanto na sala de aula quanto no ambiente social, além de o professor dar prioridade para todos falar, e não apenas um. Já a segunda delas é a habilidade para Estudo. Wildgrube et al explica que esta trata-se da habilidade da autoconscientização dos docentes.

[...] Os professores têm que mostrar aos alunos que a aula não precisa em sua essência ser dirigida completamente pelo professor, mas que este seja o mediador de um processo de construção do conhecimento de forma coletiva e agradável. (WILDGRUBE et al, 2018, n.p.)

David (2017, p. 80) faz uma observação em relação aos professores de inglês. Segundo o autor, o docente de LI não se preocupa com a formação social do discente. "Nem sempre as discussões giram em torno das atitudes dos alunos no convívio social. Parece que a missão de educar se delega às disciplinas básicas no ensino regular e às famílias" (DAVID, 2017, p. 80).

Outro aspecto importante que Letícia destacou com relação à professora é que quando Fernanda ia explicar o conteúdo, os alunos ficavam quietos e 
prestavam atenção, se alguém não se comportasse, ela chamava a atenção e, logo, o indivíduo mudava seu comportamento. As classes tinham uma ótima interação entre professor-aluno. A residente disse que ficou impressionada com os estudantes, pois eram bastante participativos durante as aulas e faziam todas as atividades propostas por Fernanda, o que muitas vezes, não acontece nas salas de aulas. Ela salienta a interação da classe com a professora um aspecto muito importante, pois faz com que o ensino-aprendizagem seja mais produtivo. Ela acrescenta que alguns alunos não tinham interesse em aprender uma segunda língua, mas mesmo assim, realizavam as atividades. Percebe-se então que a professora apresentava domínio de sala.

Levando em consideração as informações supracitadas, podermos considerar quem este ensino é fortemente instrumental, ou seja, sustentado numa concepção de língua enquanto sistema, o que, consequentemente, direciona o professor a essa práxis pedagógica. Essa prática é construída, de acordo com Caldeira e Zaidan (2013, p. 20), "no cotidiano da ação docente e nela estão presentes, simultaneamente, ações práticas mecânicas e repetitivas, necessárias ao desenvolvimento do trabalho do professor e à sua sobrevivência nesse espaço [...]".

Dessa forma, muitas vezes, o docente desmotivado, ensina apenas gramática, pois sabe que a maioria dos alunos da escola pública não tem o mínimo em LI. David (2017, p. 80) acrescenta que os professores, em sua maioria, consideram que os alunos são incapazes de aprender outro idioma, uma vez que possuem dificuldade de aprender o próprio português. Segundo a revista online Educação (2015), para a professora Márcia Matiko Okudi -antiga professora da rede pública estadual de São Paulo- "Os alunos são muito carentes, as classes têm níveis muito diferentes, faltam professores que deem atenção aos alunos. No ensino médio a situação é ainda pior."

\section{Aprendizagens e desafios}

Ao longo dessa experiência, a graduanda refletiu criticamente sobre a sua participação no programa e apontou alguns aprendizagens e desafios de acordo com seus conhecimentos, tanto prático quanto teórico. Segundo 
Wengzynski e Tozetto (2012, p. 5) refletir sobre a prática e as relações que acontecem a partir desta faz com que tenhamos novos conceitos no campo do trabalho do docente. De acordo as autoras (2012, apud PÉREZ GÓMEZ (1998, p. 372) a reflexão

É uma forma de praticar a crítica com o objetivo de provocar a emancipação das pessoas, quando descobrem que tanto o conhecimento quanto a prática educativa são construções sociais da realidade, que respondem a interesses políticos e econômicos contingentes a um espaço e a um tempo e que, portanto, podem mudar historicamente.

Letícia relatou que um dos desafios enfrentado durante o programa se deu pelo fato de que as turmas dos $3^{\circ}$ anos eram opostas, aspecto interessante a ser apresentado, visto que ambas na mesma série e no mesmo colégio, mas com características diferentes. $\mathrm{O} 3^{\circ}$ ano $\mathrm{A}$ era uma classe mais reservada, eles não interagiam muito nem tinham muita facilidade com a língua inglesa e pediam pouca ajuda. Já a turma do $3^{\circ} \mathrm{B}$ era muito participativa em todas as atividades, houve uma ótima interação entre ela e seus alunos, eles tiravam dúvidas e até levavam, para a sala de aula, dúvidas em LI que eles tinham de algum conteúdo gramatical que não era o conteúdo estudado, mas tinham interesse em aprender. A residente também disse que, no início, quando foi escolher a classe, ficou receosa, visto que nunca tinha lecionado para alunos do ensino médio e pensava que poderia ser mais difícil trabalhar com eles do que com crianças. Todavia, suas expectativas iniciais foram reconfiguradas, visto que sua vivência nas turmas dos $3^{\circ}$ anos foi surpreendente.

Ademais, ela acrescenta que outro desafio enfrentado foi em relação à habilidade de listening, pois, em grande parte das redes estaduais, não há equipamentos apropriados para passar uma música ou até mesmo assistir um vídeo. Como exemplo, a acadêmica preparou uma atividade que envolvia filme a fim de desenvolver a habilidade supracitada e de proporcionar uma aula mais dinâmica, porém, não foi possível realizá-la, visto que houve uma falta de material. Esta é uma amostra do porquê o ensino de uma língua estrangeira, muitas vezes, é falho na educação pública. Também é evidente que o pouco investimento nas escolas acarreta em um mal ensino-aprendizagem. 
Já em relação aos seus principais aprendizados, ela pontuou como a primeira a preparação dos materiais, como os planos de aula e a sequência didática. As atividades de colaboração, que foram aplicadas ao longo do Residência Pedagógica, tiveram um ótimo desenvolvimento, até mesmo, na maioria delas, com a turma do $3^{\circ} \mathrm{A}$, pois ambas as classes foram cooperativas e houve bastante interação. Quando ela preparava as atividades, sempre selecionava os exercícios atraentes aos alunos, que fossem bons para tentar praticar todas as habilidades do inglês, mas, principalmente, exercícios com as habilidades que os alunos não tinham muito contato, e que contribuíssem em melhores resultados na aprendizagem da turma. Alguns do conteúdo abordados foram: Present Perfect, Kinds Of Movies, Summary, Adjectives, Superlative And Comparative, And Review.

A título de exemplo Letícia descreveu resumidamente algumas das atividades aplicadas. Para a explicação do Present Perfect foi utilizada a música I Still Haven't Found What I'm Looking For, da banda U2, com o intuito dos alunos desenvolverem o listening. Já na explicação dos Adjectives, ela relatou que foi solicitado aos alunos para que formassem duplas com o propósito de montarem um diagrama "Discuss the following questions with a partner. Complete the diagram about how you think movies influence culture around the world." Essa atividade focou na reflexão dos alunos para que baseados nos seus conhecimentos prévios respondessem a atividade e, a partir disso, ela explicasse o uso dos adjetivos.

Já na abordagem do Kinds of Movies, a residente introduz o conteúdo discutindo oralmente algumas questões sobre filmes em geral como:

1. Do you like movies?

2. Is there any kind of movie that you do not like at all?

3. Where do you generally watch movies? At home or at the cinema?

4. How often do you watch movies?

5. What is your favorite movie?

6. What is your favorite kind of movie?

As perguntas tinham a finalidade de fazer com que os alunos colocassem em prática o speaking. O último exemplo é em relação ao 
Superlative and Comparative. Foi entregue aos alunos um texto e, a partir dele, a residente questionou os alunos a respeito das partes destacadas no texto. Foram feitas perguntas com o objetivo de ativar os conhecimentos prévios referente à gramática que eles estudariam.

A residente também destacou lecionar e auxiliar a professora da turma como um de seus aprendizados, isto é, no sentido de aprimorar sua prática docente e, assim, melhorar a qualidade do ensino e aprendizagem dos alunos no processo de aquisição de uma língua estrangeira. Ela cita que conhecer a turma, planejar sua aula de acordo com os diferentes níveis de inglês, conhecer aspectos metodológicos e solucionar problemas, que aparecem durante a aula, foram algumas das aprendizagens que ela adquiriu ao longo da sua atuação dentro da sala de aula, tanto como professora quanto auxiliar de sua preceptora. Também relatou que, ao lecionar, ela compreendeu que o professor tem o papel fundamental de levar atividades variadas à classe a fim de que eles atinjam todos os aprendizes, pois, cada indivíduo tem sua forma de assimilar o conteúdo.

De acordo com Saldanha, Zamproni e Batista (2016, p. 1-2) há diferentes estilos de aprendizagem, que são apresentados de diferentes formas e classificações. Dentre estas formas destaca-se o método VAC (visual, auditivo e cinestésico). Esta teoria foi desenvolvida por Fernald e Keller e Orton. Elas explicam que o a) Visual: os alunos que possuem habilidades de conhecer, interpretar e diferenciar os estímulos recebidos visualmente. Por meio da visualização das imagens, eles estabelecem relações entre ideias e abstraem conceitos; b) Auditivo: os discentes desenvolvem suas habilidades de conhecer e interpretar os estímulos recebidos pela palavra falada, sons e ruídos, organizando suas ideias, conceitos e abstrações a partir da linguagem falada; c) Cinestésico: os estudantes possuem habilidades de conhecer, interpretar e diferenciar os estímulos recebidos pelo movimento corporal (SALDANHA; ZAMPRONI; BATISTA, 2016, p. 1-2).

Letícia relatou que tentou abarcar todos os diferentes tipos de aprendizagens em suas atividades com o objetivo de atingir todos os alunos, oportunizando a eles a possibilidade de assimilação e de aprendizado do 
conteúdo. Ela citou exemplos de atividades que ela utilizou os métodos supracitados. O primeiro estilo de aprendizagem, o visual, pode ser visto na atividade do Kinds of movies, visto que foi utilizado slides, por exemplo, com imagens de filmes. O segundo método, o auditivo, faz parte dos conteúdos que foram trabalhados com música e, o último, o cinestésico, tem como exemplo uma aula em que ela trabalhou vocabulário e para o conteúdo ser assimilado, ela propôs a mímica como atividade.

Ademais, para a conclusão da residência, os responsáveis pelo programa solicitaram que os integrantes fizessem um trabalho final. Assim, Leticia aproveitou um evento que aconteceria no final do ano no colégio, intitulado O III Festival Arte e Movimento, que ocorreu no mês novembro de 2019. A acadêmica em conjunto com outros residentes, que também atuavam nas turmas dos $3^{\circ}$ anos, ensaiaram os alunos para cantarem e dançarem músicas em inglês.

Os ensaios aconteceram durante algumas aulas de inglês e de outras disciplinas, visto que o colégio organizou os horários que cada turma poderia ensaiar para não haver tumulto. Letícia conta que os alunos ficaram responsáveis na escolha das músicas. Depois, ela e os outros residentes exploraram as músicas, a título de exemplo, treino da pronúncia, significado das palavras. No primeiro dia do festival, os alunos do ensino médio fizeram suas apresentações e, no segundo dia, os alunos no ensino fundamental. $O$ evento do ensino médio, aconteceu em um centro universitário particular de Maringá. Leticia relatou que foi um evento maravilhoso, todos os alunos fizeram lindas apresentações.

É inegável que experiências como esta relatada são únicas na trajetória acadêmica dos graduandos. Segundo Manchur, Suriani e Cunha (2013, p. 339) "Durante a prática docente não existe uma receita pronta para se aplicar, mas com estrutura e metodologias constantes pautadas nas diferentes realidades é possível planejar e desenvolver uma docência que contemple os objetivos de educação". Assim, vivencias como estas são extremamente enriquecedoras e propiciam muitas oportunidades para o desenvolvimento na formação dos 
futuros docentes. Além de abrir as portas das escolas para os graduandos, este programa é um caminho para a construção e aquisição de conhecimentos.

Conforme Manchur, Suriani e Cunha (2013, p. 339), mesmo que ao longo do curso de graduação seja repleto de aprendizagens, é insuficiente para o futuro professor. Os autores acrescentam que os conhecimentos "vão sendo construídos e adquiridos ao exercer a profissão, tornando-se fundamental a participação em projetos que objetivam a prática docente [...]" (MANCHUR; SURIANI; CUNHA, 2013, p. 339). Logo, essas experiências revelam a importância da participação dos discentes em projetos como o Residência Pedagógica, que visam a prática docente, uma vez que contribuem significativamente na formação dos acadêmicos.

Por fim, Letícia expõe que a reflexão sobre a prática e a possibilidade de compreensão desta para além da sala de aula é um alicerce na transformação do contexto escolar. Assim, quando o estagiário entra em contato o seu real futuro ambiente de trabalho, ao observar as aulas, ele começa a refletir sobre aquela situação, o que deve ou não fazer e até mesmo começa a pensar em soluções para tais problemas que podem surgir ao longo de seu exercício.

\section{Considerações finais}

O presente trabalho relatou uma experiência de formação docente inicial vivenciada no Programa de Residência Pedagógica. O interesse central deste relato foi compartilhar uma experiência bem-sucedida, realizada por meio de um programa universitário. Foi evidente que estas ações de aproximar as universidades com a comunidade, desenvolvendo pesquisa e ensinando numa troca dialógica e direcionada para a comunidade, tal como o Programa de Residência Pedagógica é de grande valor aos discentes de licenciatura. Além disso, levando em consideração as experiências, nota-se que o professor também é pesquisador, visto que ele reflete no aprimoramento de seu ensino.

Com essa rica experiência dentro da sala de aula, Letícia aprimorou significativamente sua prática docente. Com o auxílio de sua preceptora adquiriu conhecimento, entendeu que existirá desafios ao longo de sua profissão, como os diferentes tipos de alunos, cada um com sua singularidade. 
Quando ela entrou em contato com o ambiente escolar, ao observar as aulas, ela começou a refletir sobre aquela situação, o que deve ou não fazer e até mesmo começou a pensar em soluções para tais problemas que poderiam surgir ao longo de seu exercício.

Dessa forma, refletir sobre as experiências vivenciadas é muito benéfico, pois todo profissional deve se atentar ao seu desempenho. Conforme Silvestre (2011, p. 3, apud HEAD; TAYLOR, 1997) o envolvimento dos professores em um processo de reflexão sobre a experiência contribui significativamente para seu desenvolvimento profissional. Desse modo, o programa é relevante no que se refere ao aperfeiçoamento dos conhecimentos e acerca do processo de ensino, além de contribuir para a construção de identidade do docente em formação inicial. O residente lida com as diferentes realidades das escolas e coloca em execução tudo que foi aprendido na universidade, isto é, unindo teoria e prática dentro de uma sala de aula.

\section{Referências}

BRASIL. Base Nacional Comum Curricular (BNCC). Educação é a Base. Brasília, MEC/CONSED/UNDIME, 2017.

CALDEIRA, A. M. S.; ZAIDAN, S. Z. Práxis pedagógica: um desafio cotidiano. Paidéia, Belo Horizonte, n. 14, p. 15-32, jan./jun., 2013.

CHARLO, B. Formação de professores: a pesquisa e a política educacional. In: PIMENTA, S. G.; GHEDIN, E. (org.). Professor reflexivo no Brasil: gênese e crítica de um conceito. 7 ed. São Paulo: Cortez, 2012. p. 103-126.

CUNHA, M. C.; MANCHUR, J.; SURIANI, A. L. A. A Contribuição de Projetos de Extensão na Formação Profissional de Graduandos de Licenciaturas. Conexão UEPG, Ponta Grossa, v. 9, n. 2, p. 334-341, jul./dez. 2013.

DAVID, R. S. O Ensino-Aprendizagem De Língua Inglesa Em Escolas Públicas: O Real E O Ideal. Pedagogia em Ação, Belo Horizonte, v. 9, n. 1, 2017.

EDITAL CAPES $n^{\circ}$ 06/2018. Programa de Residência Pedagógica. Chamada Pública para apresentação de propostas no âmbito do Programa de Residência Pedagógica.

FERNANDES, J. H. L.; GOETTEMS, L.; HUBERT, I. A. Formação e inicial e continuada dos professores. In: SEMINÁRIO INTERNACIONAL DE EDUCAÇÃO NO MERCOSUL, 17., 2015, Cruz Alta. Anais [...] Cruz Alta: UNICRUZ, 2015, s/p. Disponível em: 
https://home.unicruz.edu.br/mercosul/pagina/anais/2015/1\%20\%20ARTIGOS/FORMACAO\%20E\%20INICIAL\%20E\%20CONTINUADA\%20D OS\%20PROFESSORES.PDF. Acesso em: 05 ago. 2020.

Programa de Residência Pedagógica. Fundação Capes, 2018. Disponível em https://capes.gov.br/educacao-basica/programa-residencia-pedagogica. Acesso em: 29 nov. 2019.

JARETA, G. Por que o ensino do inglês não decola no Brasil. Educação, 2015. Disponível em: https://revistaeducacao.com.br/2015/11/04/por-que-o-ensinodo-ingles-nao-decola-no-brasil/. Acesso em: 3 out. 2020.

LIBÂNEO, J. C. Reflexidade e formação de professores: outra oscilação do pensamento pedagógico brasileiro?. In: PIMENTA, S. G.; GHEDIN, E. (orgs.). Professor reflexivo no Brasil: gênese e crítica de um conceito. 7 ed. São Paulo: Cortez, 2012. p. 63-93.

PUPIM, P. Pibid e Residência Pedagógica aproximam a UEM da Educação Básica. Assessoria de comunicação social, Maringá, 17. ago. 2018. Disponível em http://www.asc.uem.br/index.php?option=com_content\&view=article\&id=22972: pibid-e-residencia-pedagogica-aproximam-a-uem-da-educacaoasica\&catid=986\&ltemid=101. Acesso em: 29 nov. 2019.

SALDANHA, C. C.; ZAMPRONI, E. C. B.; BATISTA, M. L. A. Estilos de aprendizagens. In: SEMANA PEDAGÓGICA. Curitiba: Secretaria da Educação do Paraná, p. 1-6, 2016. Disponível em: http://www.gestaoescolar.diaadia.pr.gov.br/arquivos/File/sem pedagogica/julho 2016/dee anexo1.pdf. Acesso em: 3 out. 2020.

SANTOS, M. C.; DONATO, M. S. R.; OLIVEIRA, M. G.; PASSONI, T. P. Leitura e criticidade no ensino de língua inglesa: relato de experiência sobre o estágio supervisionado. Revista eletrônica pro-docência/UEL, Londrina, v. 1, n. 3, p. 123-132 jan-jun. 2013. Disponível em: http://www.uel.br/revistas/prodocenciafope/pages/arquivos/Volume3/SANTOSDONATO-OLIVEIRA-PASSONI.pdf. Acesso em: 29 nov. 2019.

SILVA, F. G.; SILVA, E. G.; QUEIROZ, J. C. A importância do professor pesquisador. In: CONGRESSO NACIONAL DE EDUCAÇÃO, 3., 2011, Natal. Anais [...] Natal: CONEDU, 2016.

SILVESTRE, V. P V. Estágio supervisionado: reflexões de alunos-professores de língua estrangeira. In: SIMPÓSIO NACIONAL DE LETRAS E LÍNGUISTICA E SIMPÓSIO INTERNACIONAL DE LETRAS E LINGUÍSTICA, 2011, Uberlândia. Anais [...] Uberlândia: EDUFU, p. 1-11, 2011.

WENGZYNSKI, D. C.; TOZETTO, S. S. A formação continuada face as suas contribuições para a docência. In: SEMINÁRIO DE PESQUISA EM EDUCAÇÃO DA REGIÃO SUL, 9., 2012, Caxias do Sul. Anais [...] Caxias do Sul: $\quad$ ANPED SUL, $2012 . \quad$ Disponível em: 
http://www.ucs.br/etc/conferencias/index.php/anpedsul/9anpedsul/paper/viewFil e/2107/513. Acesso em: 05 ago. 2020.

WILDGRUBE, R.; DREHER, G. M.; SOUZA, M. A.; NARDI, N. L. O Trabalho Integrado Das Habilidades Lingüisticas Em Língua Inglesa. Voz das Letras, Santa Catarina: Concórdia, n. 10, p. n. 2008. Disponível em: http://www.educadores.diaadia.pr.gov.br/arquivos/File/2010/artigos_teses/Ingle s/Wildgrube.pdf. Acesso em: 03 out. 2020.

\section{Sobre os autores}

\section{Flávia Bissi de Oliveira}

flaviabissi@hotmail.com

Graduanda do curso de Letras Português/Inglês e literaturas correspondentes na Universidade Estadual de Maringá (UEM). Desenvolveu dois Projetos de Iniciação Científica (PIC). O primeiro intitulado: O programa Paraná Fala Inglês em uma universidade pública paranaense: a visão de seus participantes, com foco no programa Paraná Fala Idiomas (PFI). O segundo PIC designado "O Vlog e o ensino e aprendizagem de Língua Portuguesa nos $8^{\circ}$ e $9^{\circ}$ anos". Suas investigações se concentram nas áreas de formação de professores e ensinoaprendizagem de línguas.

\section{Sandra Maria Coelho de Souza Moser}

mosersmcs@hotmail.com

Possui graduação em Letras pela Universidade Estadual de Maringá (1976), Mestrado em Linguística Aplicada pela Universidade Estadual de Campinas (1995) e Doutorado pela Universidade do Estado de São Paulo (2005). Coordenadora do Curso de especialização: Formação de professor de Língua Estrangeira: Práticas reflexivas, metodológicas e tradutórias. Foi coordenadora do Curso de Letras da Universidade Estadual de Maringá em (1998 a 2001) e (2004 a 2008). Coordena o Projeto de Ensino Assessoria Pedagógica de Português como Língua Estrangeira (APPLE). Coordena o Projeto de Extensão (permanente) Projeto de Língua Inglesa (PELI). Coordena o Projeto de Extensão a Formação Profissional do Professor de Língua Inglesa desde 2007 no programa PDE do Estado do Paraná. 